\title{
Los montículos Oquendo durante el Periodo Intermedio Temprano en el valle bajo del Chillón, costa central del Perú ${ }^{1}$
}

\section{The Oquendo mounds during the Early Intermediate Period in the lower valley of Chillón, central coast of Peru}

\author{
Erick Ernesto Acero Shapiama \\ https://orcid.org/0000-0003-0361-6700 \\ Universidad Nacional Federico Villarreal \\ eernest.acero@gmail.com \\ Lisseth F. Rojas Pelayo \\ https://orcid.org/0000-0002-0678-477X \\ Universidad Nacional Federico Villarreal \\ liropelayo@gmail.com
}

\section{RESUMEN}

Las excavaciones realizadas por el Programa de Arqueología de la Universidad Nacional Federico Villarreal (UNFV) se centraron en el área de Oquendo, valle bajo del río Chillón, Costa Central del Perú, a finales de los años 90's; realizándose así intervenciones en los montículos 4, 5 y 6, cuyos estratos contenían fragmentaria de cerámica Blanco sobre Rojo (B/R), restos de materiales orgánicos (desechos de consumo), actividades de combustión (fogón) y otros, siendo asociados a ocupaciones de carácter temporal. Estos datos han permitido realizar comparaciones con algunos sitios de los valles de Lurín, Chancay y Rímac (Patterson, 1966a, 1966b, y 2014; Córdova 1999; Goldhausen, 2014; Acero, 2015 y otros), enmarcándose en la proble-

1. En el presente artículo se expone a manera de resumen los aportes presentados en la tesis de licenciatura "Investigaciones arqueológicas en Oquendo, valle bajo del Chillón: La secuencia del utillaje identificado en los montículos 4, 5 y 6” (Acero, 2015), al cual se han realizado pequeños cambios que no modifican la totalidad de la información presentada.

(C) Los autores. Este artículo es publicado por Arqueología y Sociedad del Museo de Arqueología y Antropología de la Universidad Nacional Mayor de San Marcos. Este es un artículo de acceso abierto, distribuido bajo los términos de la licencia Creative Commons Atribución 4.0 Internacional (CC BY 4.0) [https: / / creativecommons. org/licenses/by/4.0/deed.es] que permite el uso, distribución y reproducción en cualquier medio, siempre que la obra original sea debidamente citada de su fuente original. 
mática de cambios culturales y la presencia de cerámica Blanco sobre Rojo, cuyo uso marcaba una popularidad con distintos matices sociales, desde la perspectiva del bajo Chillón durante el Periodo Intermedio Temprano (P.I.T.).

Palabras clave: Cerámica B/R; montículos; Oquendo; valle bajo del Chillón; Periodo Intermedio Temprano.

\section{ABSTRACT}

The excavations realized by the Archeological Program of the Federico Villarreal University, were focused in the Oquendo area, lower valley of the Chillon river, central coast of Peru at the end of 90's; it convered excavations in the mounds: 4, 5 and 6; its stratums contained white on red pottery, organic materials, combustion activities (pit) and others; all of them associated a temporal occupations. This data permitted us to make comparisons with certain sites of the Lurin valley, Chancay and Rimac rivers (Patterson 1966a, 1966b, y 2014; Córdova 1999; Goldhausen 2014; Acero 2015 and others), which they kept into the culture dynamic problematic and the white on red pottery presence, its used mean popularity with differentes nuances, since the perspective focused in the Chillon valley during the Early Intermediate Period.

Keywords: Pottery B/R; Mouds; Oquendo; Chillón valley; Late Period Intermediate.

Recibido: 05/01/2018 - Aceptado: 13/08/2020 - Publicado: 25/06/2021

\section{OQUENDO Y SU ENTORNO ${ }^{2}$}

Oquendo en la actualidad se ubica en la provincia constitucional del Callao, región de Lima en Perú (Ver figura 01); localizada entre las coordenadas UTM 8' 675, $398 \mathrm{~N}$ y 268, 735 E., e inscrita en la carta nacional Chancay 24 - i, escala 1/100, 000 (Acero, 2010a). Geográficamente es parte del valle bajo del río Chillón (entre los 0 a 500 m s. n. m.), región natural Chala (Pulgar Vidal, 1987) o ecorregión del desierto del Pacifico (Brag, 1987; Acero, 2010a, 2010b), cuyo entorno natural se forma a partir de extensos suelos que provienen de depósitos fluviales del río y sus afluentes, denominado por la ONERN (1975) como paisaje aluvial, tipificado por terrazas bajas e intermedias que representan abanicos y conos aluviales (formaciones locales) (ONERN 1975). En el valle bajo se ha distinguido un entorno paisajístico que determinan “(...) dos zonas de recursos naturales explotables (el área del litoral marino y el área agrícola del valle) que han sido de gran importancia como fuente

2. La zona donde se emplazaron los montículos Oquendo (M4, M5 y M6) corresponde a la zona agrícola, que para la época prehispánica debió presentar mejores condiciones climáticas, ecológicas y/o geográficas, lo que contribuyó al establecimiento de poblaciones, que se asentaron en los extensos territorios del valle, desde los conos de deyección hasta la bahía de Ancón (Stumer, 1954 a y b; Lanning, 1963; Acero, 2015). 


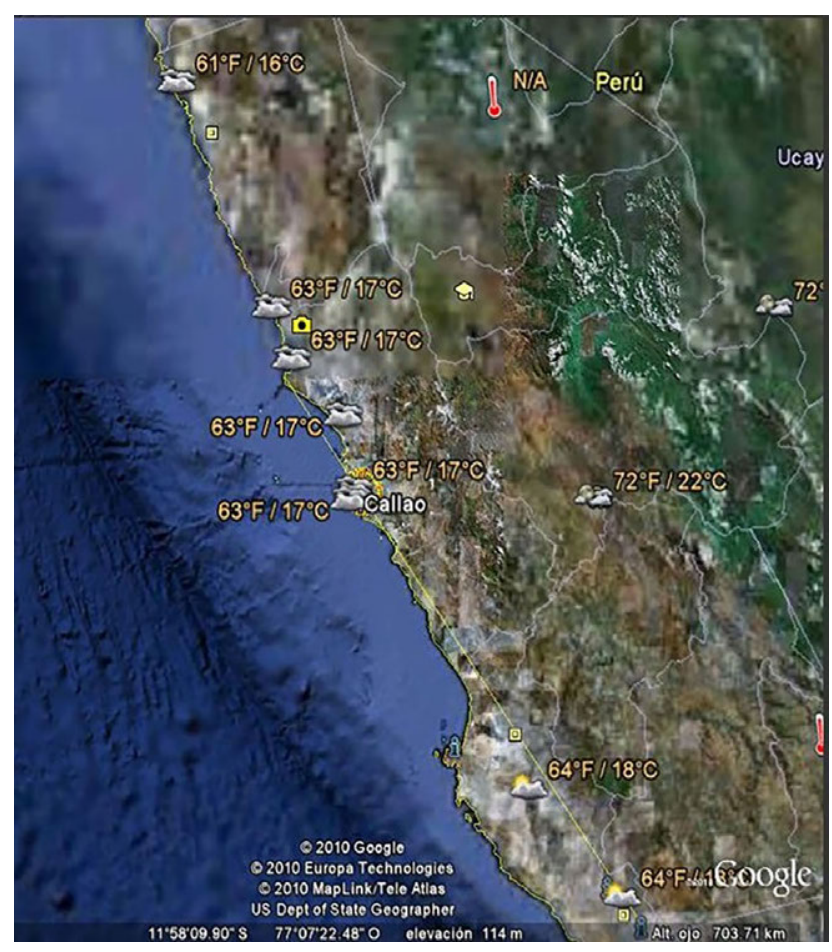

Figura 01. Vista General de la Provincia del Callao y zonas geográficas; el litoral marino y el área costeños.

de alimentos para las primeras poblaciones prehispánicas y que es observado hasta la actualidad" (Acero, 2015, p. 29).

La economía del litoral marino (entre la desembocadura del río Chillón hasta Ancón), presenta playas arenosas interrumpidas por el Cerro El Perro, formándose un litoral de aspecto rocoso (ONERN 1975), desde donde se podían obtener recursos marinos como variadas especies de peces, bivalvos, gasterópodos, entre otros (mediante la pesca y la recolecta); mientras que en la zona agrícola ${ }^{2}$, se presentan extensos campos de cultivo, numerosos manantiales o puquios, importantes en la parte baja del valle, producto de la napa freática (vista de manera casi superficial), y otros de menor importancia, presentes en el Cerro Choque (Cerca Puente Piedra) y en Aznapuquio (Hacienda Naranjal y Chuquitanta) (Paredes, 2000).

La variación climática del valle bajo es de tipo desierto subtropical (extremadamente árido y semiárido), cuya temperatura media oscila alrededor de los $18.6^{\circ}$ C (aproximadamente), siendo óptimo para la formación de densas neblinas que contribuyen a la proliferación de vegetación estacional denominada "lomas" (en- 
tre los meses de junio y noviembre), diferenciadas en lomas negras (al este del río Chillón), y lomas en Carabayllo (al Sur de San Diego) (ONERN 1970; CDIAG 1993; Pulgar Vidal, 1987, 1996; INRENA 1999).

\section{LAS INVESTIGACIONES EN OQUENDO 3}

Las investigaciones en Oquendo iniciaron a finales de los años 90, realizándose un reconocimiento del valle bajo del río Chillón (cerros aledaños, conos de deyección y llanura aluvial), identificándose una diversidad de material cerámico disperso en superficie (alfarería del Horizonte Temprano, esporádicamente, Periodo Intermedio Temprano, poca presencia Lima, e Intermedio Tardío, en su mayoría Chancay) y registrándose componentes culturales como conchales y construcciones arquitectónicas: los caminos epimurales que circundan gran parte del área de Oquendo, el Palacio Oquendo, los montículos $1-6$, conchales en cerro Oquendo y otros, que definen la zona como un complejo arqueológico, que tuvo un largo proceso de ocupación (Ver figura 02); muchos de los componentes reconocidos se encuentran dentro de las actuales propiedades, notándose incluso afectaciones (seccionamientos por el avance urbano, ampliación de tierras de cultivo, huaqueo, entre otros). (Ver figura 03).

Tras el reconocimiento se iniciaron los trabajos en una sección de Oquendo, seleccionando los M4, M5, M6 (ver figura 04), cuyos alrededores denotaban colindancia al norte con el Cerro Oquendo (señal Oquendo), al sureste con la señal del Cerro Candela, al este con el sitio de Chuquitanta y al oeste con la carretera a Ventanilla (Av. Néstor Gambeta). Las excavaciones reportaron estratos que permitieron reconstruir el proceso de ocupación independiente en cada montículo. A continuación se detalla:

El Montículo 4 tiene forma semitriangular, con un largo de $36 \mathrm{~m}$ y una altura es de $1.57 \mathrm{~m}$ (tomado desde la parte elevada central), cuya orientación va de suroeste a noreste (ver figura 05). Las excavaciones fueron realizadas en lateral, emplazándose las trincheras T3 de $4 \mathrm{~m}^{2}$ y T4 de $18 \mathrm{~m}^{2}$, cuyo reporte estratigráfico permitió reconocer un estrato arenoso inferior (UE11), sin componente cultural alguno, siendo considerado como suelo estéril. El estrato anterior ha sido cubierto por una acumulación muy arcillosa que presenta dos niveles estratigráficos: el primero (UE10), denota ser parte del arrastre original denominado $1^{\circ}$ marcador natural; mientras el segundo (UE9), correspondiente es identificado como la continuidad o rezagos denominado $2^{\circ}$ marcador natural, interpretados como densas y amplias capas acumuladas durante micro ENSOS, provenientes de los conos de deyección de los cerros aledaños, formándose así el suelo natural de ese tiempo en Oquendo.

3. En el M6 se localizaron las trinchera 1, 2 y trinchera central (entre las mencionadas anteriormente); en la superficie del M4 se presentó la trinchera 3 y 4; finalmente en el M5 se dispuso la trinchera 5. Cada trinchera de excavación presentaba una variedad de dimensiones que van desde los $2 \times 1 \mathrm{~m}$ hasta las $8 \times 1 \mathrm{~m}$ siendo controlados estratigráficamente por medio de un BM referencial con valor de $100 \mathrm{~m} \mathrm{s.} \mathrm{n.} \mathrm{m.}$ 


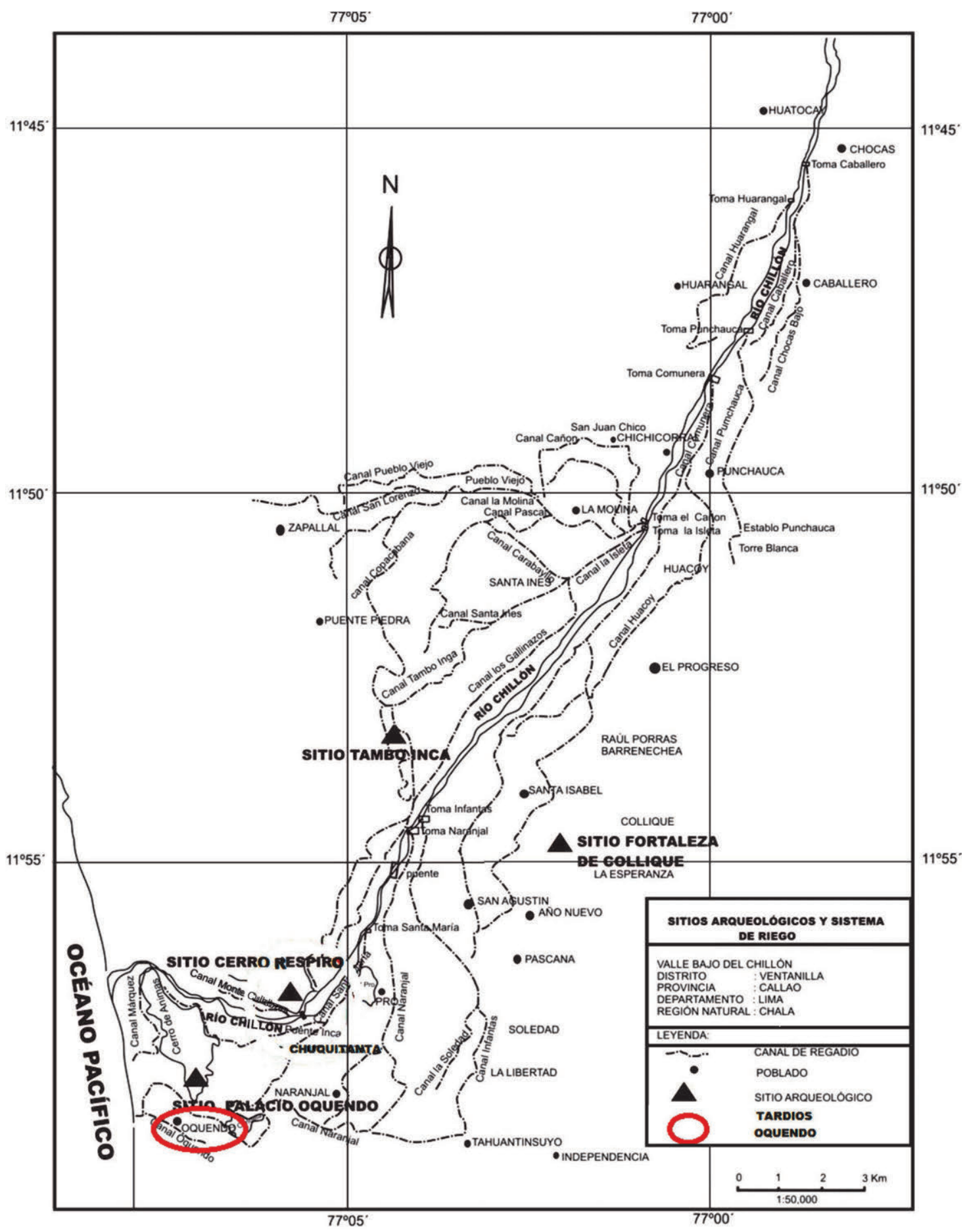

Figura 02. Área del valle bajo del Chillón donde se localizan algunos sitios tempranos y tardíos. 


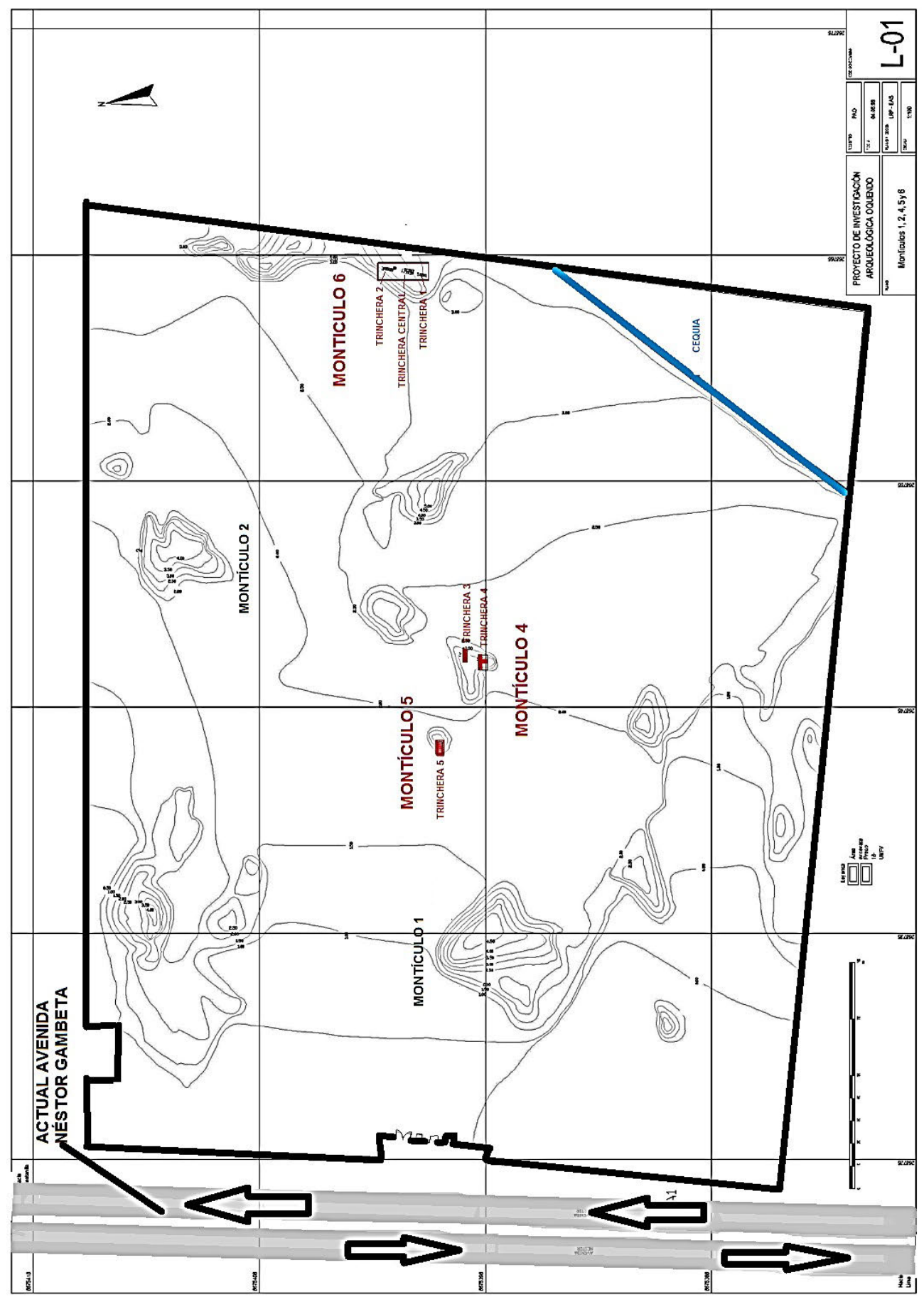

3. Vista general del Predio 18 donde se ubican los montículos 


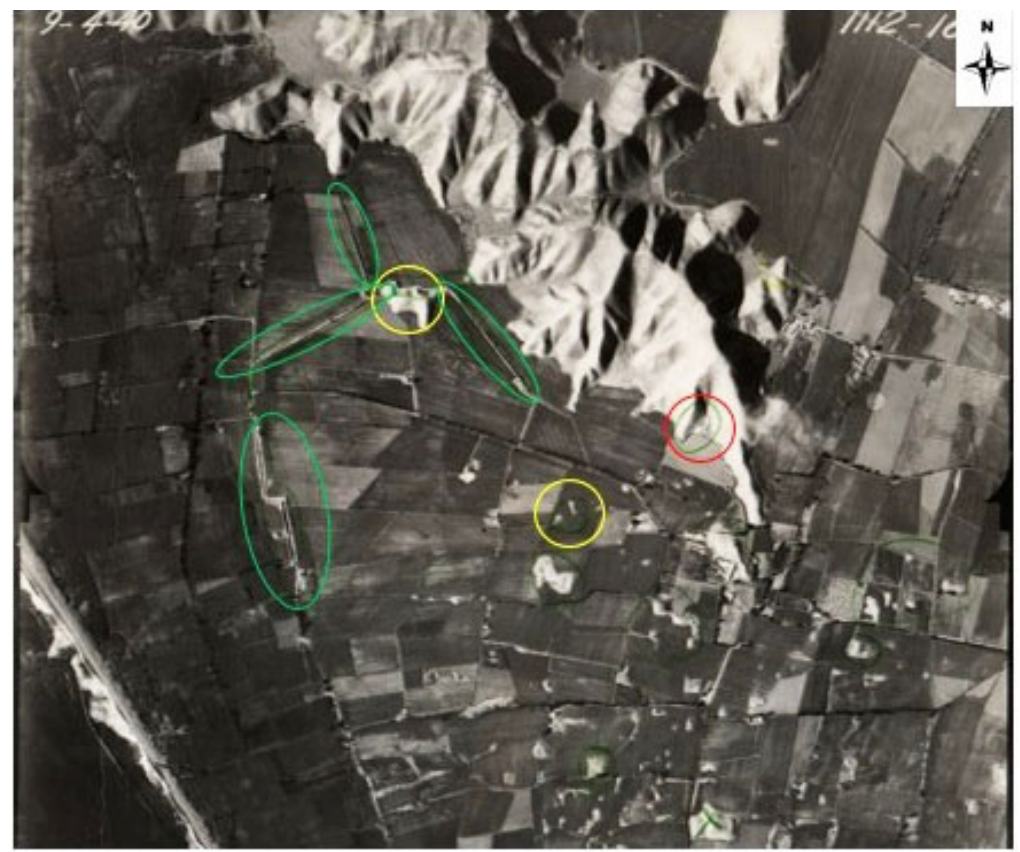

Figura 04. Área de Oquendo con amplias tierras de cultivo: montículos (color amarillo), El Palacio Oquendo (color rojo) y caminos epimurales (color verde).

El reporte estratigráfico del perfil $\mathrm{N}$ de la $\mathrm{T} 4$ permitió reconocer que sobre el marcador natural se acumularon 3 niveles de estratos culturales (UE 13, 8 y 7), que contenían escasos componentes, los cuales formaron los iniciales rellenos constructivos base del montículo. Los rellenos constructivos posteriormente fueron cubiertos por un lecho de material orgánico amplio y disperso (UE6), una estructura de planta circular (UE4-fogón constituido por piedras redondeadas ordenadas), densos restos de combustión (UE5-quema dispersa) y fragmentaría de cerámica (B/R), cuyos indicadores demuestran que hubo un largo proceso y continua ocupación (ver figura 06); siendo interrumpida tras generarse 3 finales procesos constructivos (UE1, 2 y 3 ) que permitieron acrecentar el volumen del montículo.

Los trabajos en el Montículo 5 permitieron delimitarlo y definir una forma semiredonda, con un largo de $11 \mathrm{~m}$ y altura promedio de $1.70 \mathrm{~m}$ (desde la superficie del campo de cultivo hasta su parte alta). Hacia el lado Oeste del montículo se ubica la trinchera 5 (T5) de $8 \mathrm{~m}^{2}$. (Ver figuras 07 y 08); las excavaciones permitieron identificar que en los niveles inferiores el suelo era muy arenoso sin componente cultural alguno (UE6), siendo de tipo natural o estéril, el cual fue cubierto por una concentración de ceniza polvorienta (UE5) donde se hallaron restos de material malacológico, siendo estos parte de los desechos de consumo dejados por los primeros pobladores. La construcción del montículo se inicia con la acumulación de un primer nivel de estrato cultural (UE3) denso conformado por arcilla mezclado con cantos 


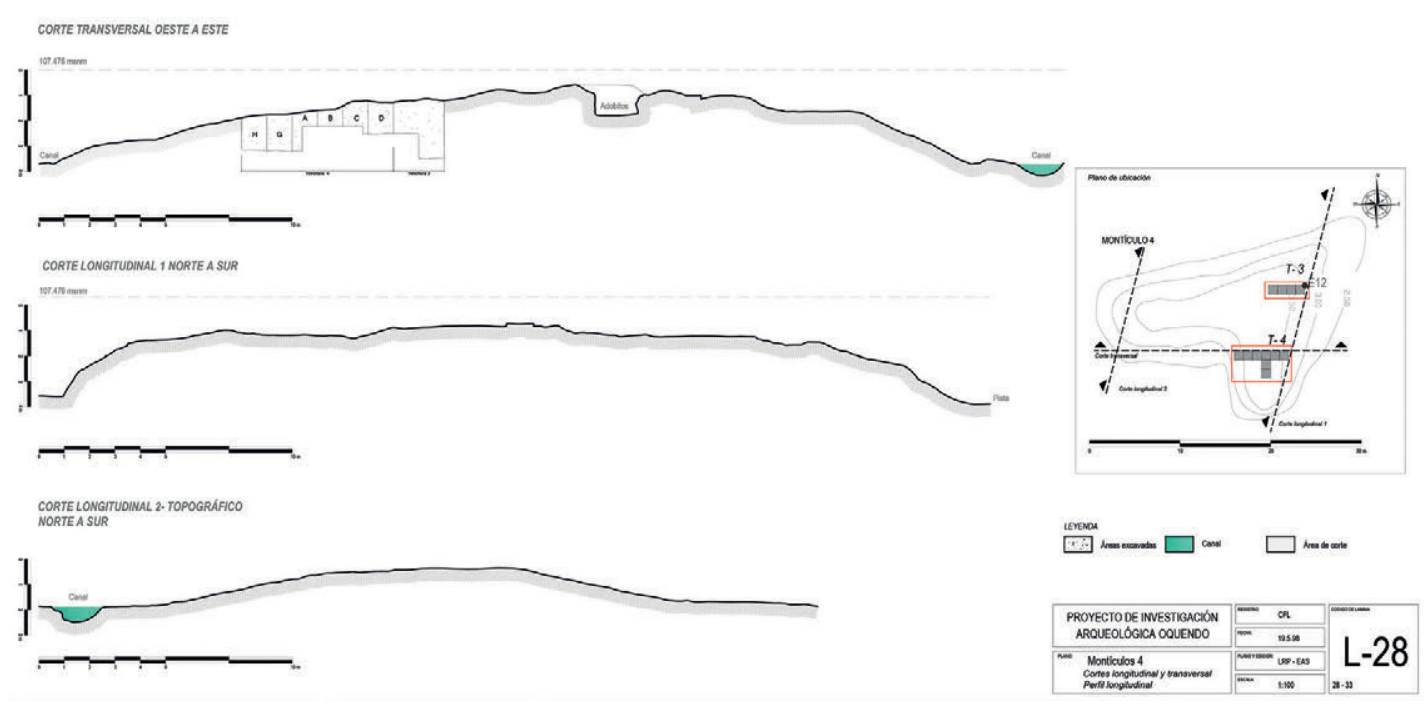

Figura 05. Vista en corte y planta del montículo M4.

rodados, presentando alguno componentes culturales, generándose así la base del M5. El perfil N permitió reconocer restos de un estrato aluviónico (UE4) que impacta y cubre parcialmente el lado Oeste del relleno base, notándose que a medida que avanza hacia el estrato arcilloso ha sido asociado al fenómeno natural ENZO (UE 9 y 10) reportado en los niveles inferiores del M4. Posterior a los eventos aluviónicos (ENSOS) se retoma el proceso constructivo (UE2), cubierto por una compactación arcillosa (UE7-con restos de ceniza visualizado en la esquina NE de la Trinchera) y una concentración de ceniza (UE8-que intruye la UE2), formándose así el nivel de ocupación temporal, pues el contexto demuestra que no hay densos estratos de ceniza o materiales de consumo acumulados que indiquen el continuo uso, asimismo no se ha encontrado estructuras asociadas que revelen actividades específicas.

El Montículo 6 tiene forma alargada, orientada de norte a sur, sobre cuya superficie irregular se ubicaron 3 trincheras: T1 de $3 \mathrm{~m}^{2}$, T2 de $10 \mathrm{~m}^{2}$ y Tc de $8 \mathrm{~m}^{2}$. A partir de las excavaciones se pudieron distinguir en la estratigrafía 2 momentos de ocupación (ver figura 09 y 10). El primero se caracterizar por conformar un estrato denso de cantos rodados y arcilla (UE5), con poca fragmentaria de cerámica B/R, cubierto por un nivel de piso arcilloso (UE10) asociado a los restos de un muro de quincha (arcilla y caña) (UE7 y 9) que debió ser parte de una antigua vivienda, encontrándose además como elemento asociado restos de un envoltorio en textil amarrado (UE8) que podría formar parte de una ofrenda (Ver figura 11). El segundo momento de ocupación es registrado a partir del estrato cultural denso (UE4) constituido por arcilla y cantos rodados, siendo considerado como un $1^{\circ}$ relleno constructivo intrusivo (UE3) 


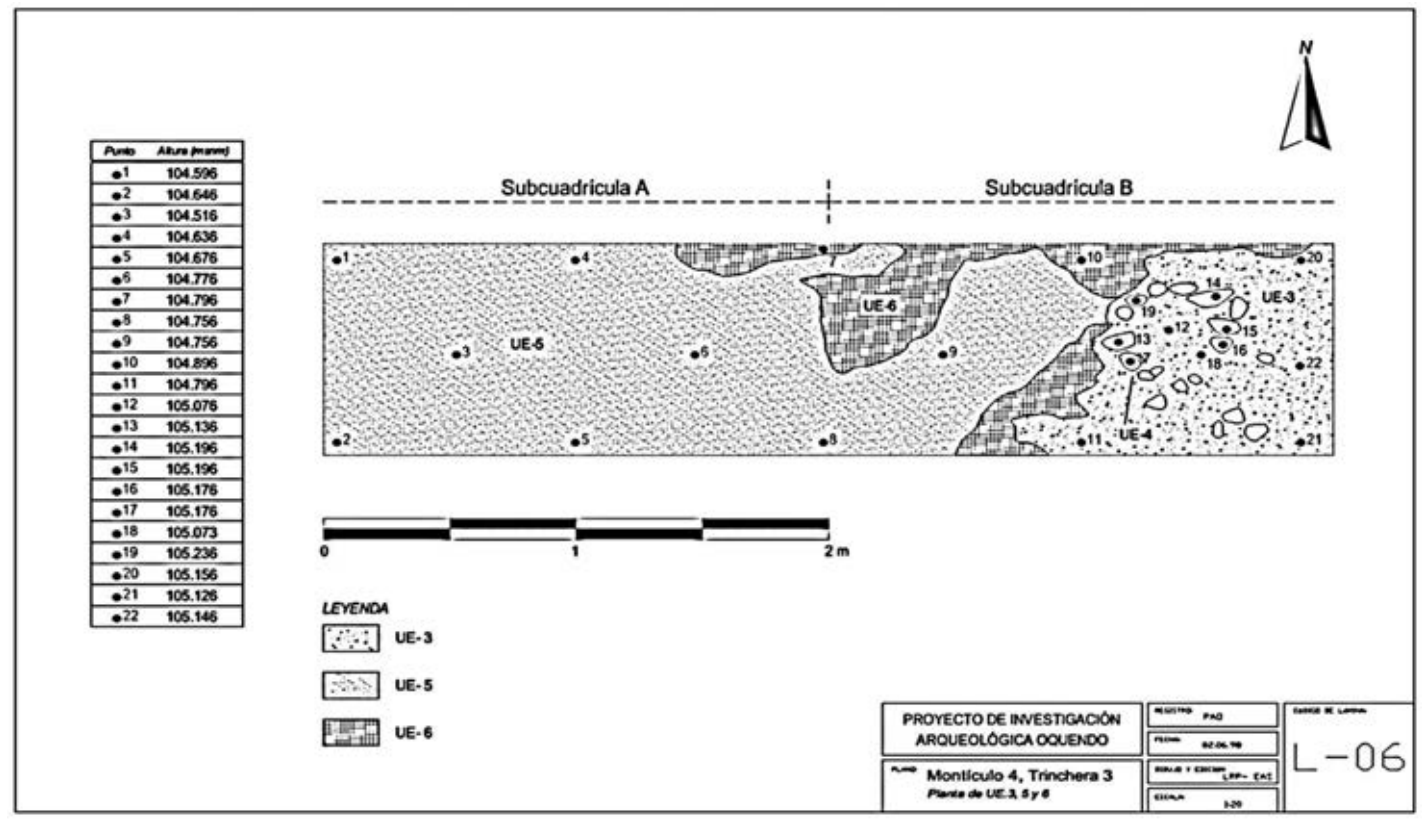

Figura 06. Vista general del fogón, ceniza y restos botánicos identificados en el M4.

CORTE TRANSVERSAL OESTE A ESTE
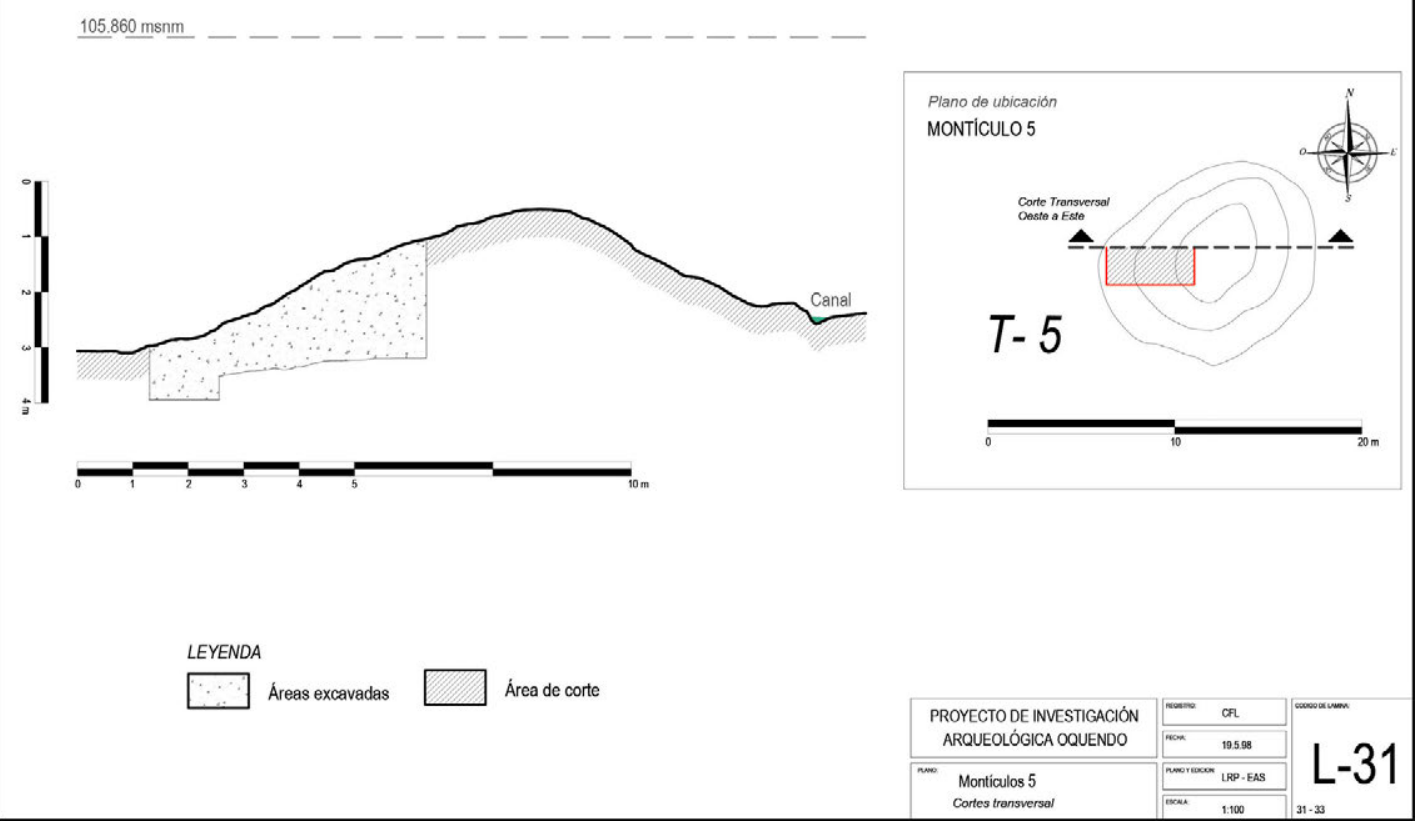

Figura 07. Vista en corte y planta del montículo M5. 


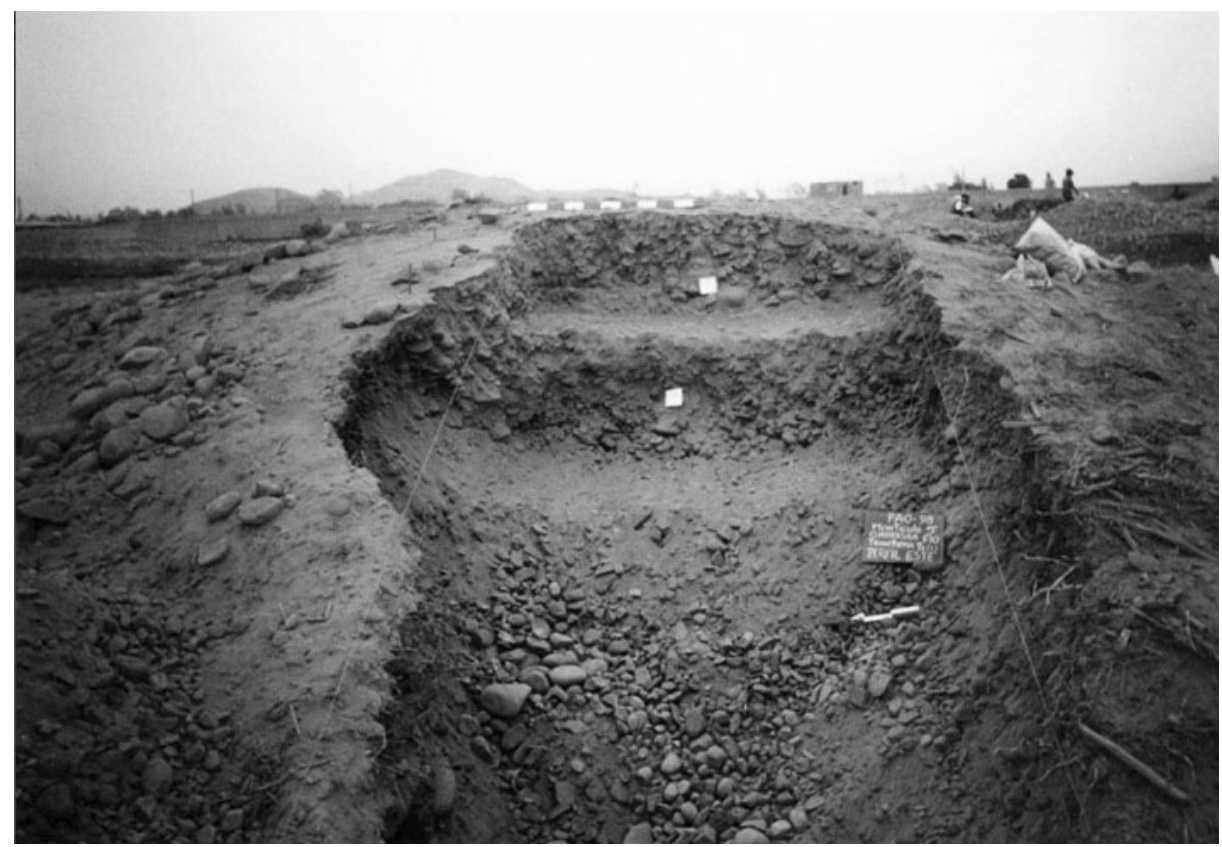

Figura 08. Vista de E a W de la subcuadrícula A y B (perfil E) del área excavada en el M5.

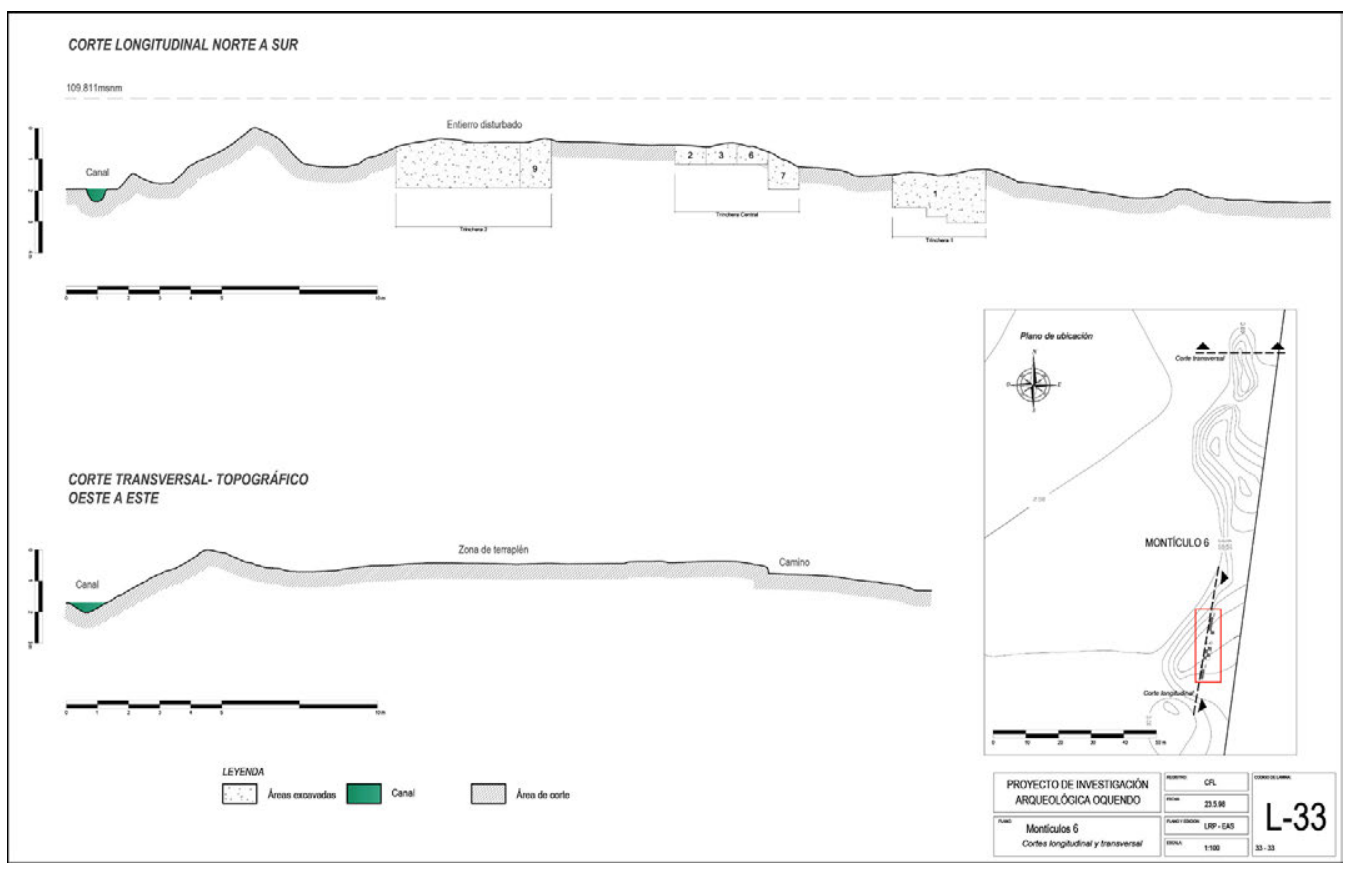

Figura 09. Vista en corte y planta del montículo M6. 


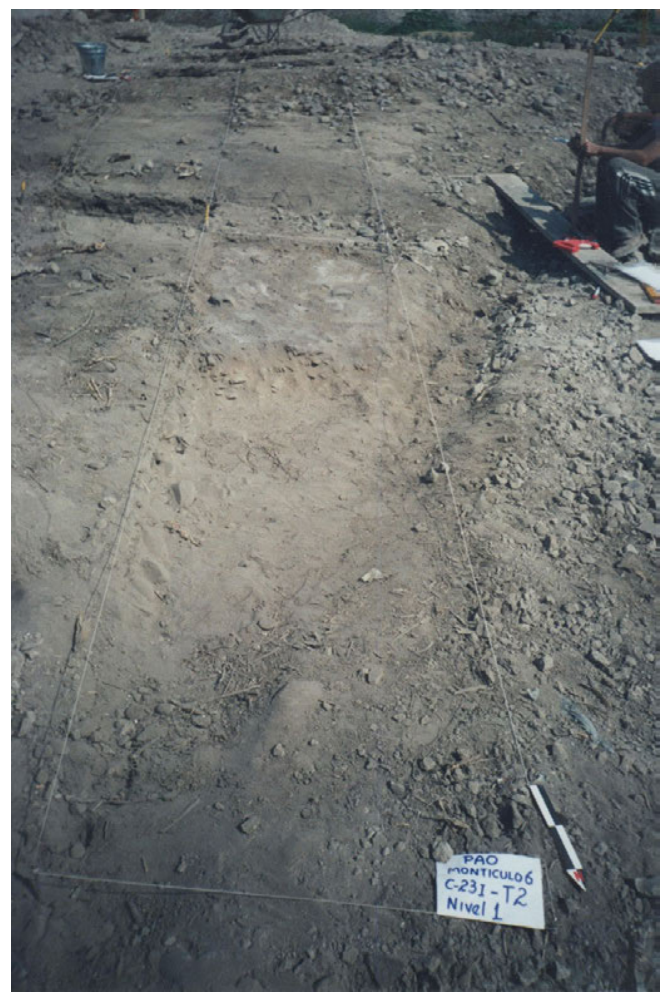

Figura 10. Vista general de la cima del montículo 6.

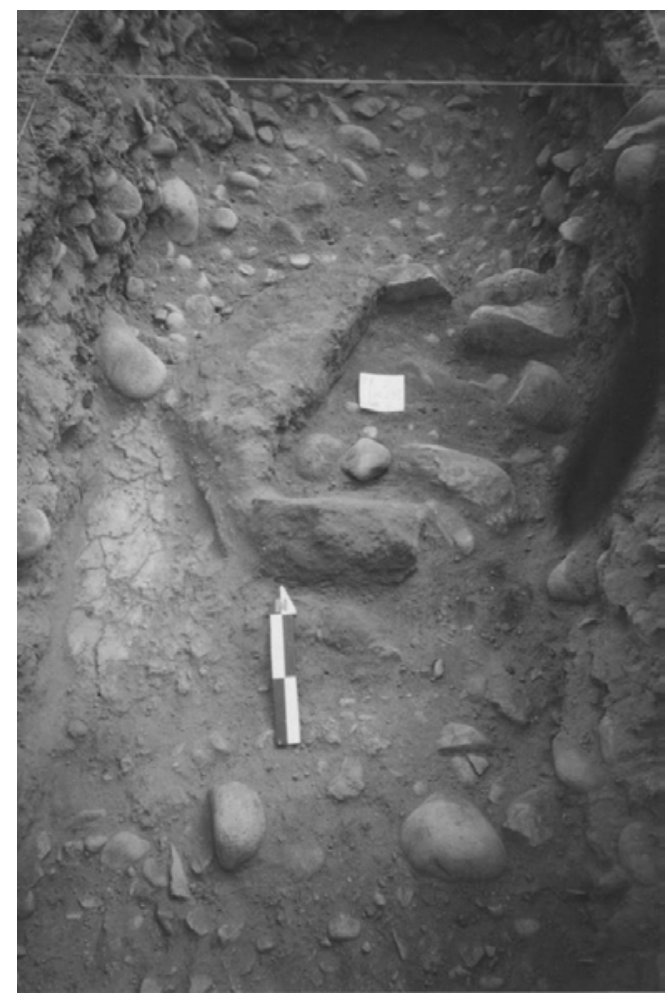

Figura 11. Detalle de los restos de arquitectura temprana $y$ ofrenda encontrada durante las excavaciones en el montículo 6.

que cubría la anterior ocupación, dentro de este había diversos materiales cerámicos del Periodo Intermedio Temprano y Tardío, y un lente de ceniza con restos de material orgánico (escasos) (UE6), que indicaban un alto grado de alteración, que incluso cubría de manera irregular parte del $2^{\circ}$ relleno constructivo que también evidenciaba alteración. De acuerdo a la estratigrafía de la T1, T2 y Tc se ha pudo reconocer 2 estratos finales, denominados $3^{\text {er }}$ y $4^{\text {to }}$ relleno constructivo, correspondiente a los rezagos superficiales, siendo definido como tal por contener evidencia de fragmentos cerámicos mezclados (tempranos y tardíos), que han sido asociados a la etapa de reocupación Tardía en el montículo.

Durante las excavaciones se recuperaron diversos elementos (fragmentos cerámicos, malacológicos, restos botánicos y otros) identificados como parte de los rellenos constructivos. Para el caso de la alfarería recuperada, contamos con diversas formas como cantaros, ollas, platos, cuencos, tazones, botellas, vasijas grandes y fragmentos de cuerpo, cuya decoración identificada es variada, resaltándose el utillaje de pigmentación Blanco / Rojo (B/R) (ver tabla 1 y 2). La cerámica ha sido analizada, determinándose 3 grupos amplios de pastas: 8 en el M4 (B, D, E, F, G, H, I y J), 4 
para el M5 (A, D, E y F) y 12 tipos en el M6 (A, B, C, D, E, F, G, H, I, J, K y L). Estas en su conjunto se caracterizan por su textura fina - homogénea y media-homogénea, de fractura concoidal e irregular, siendo recta en un solo caso. Las inclusiones registradas corresponden al feldespato, mica, cuarzo y arena de grano medio, grano muy fino y fino, de forma redondeada y angular ${ }^{4}$ (Ver tabla 03). El análisis además permitió diferenciar que el utillaje denotaba dos tipos de cocción, uno oxidante y otra reductora (sin defecto de cocción y otro con núcleo de márgenes difusos), lo que indica que hubo conocimiento sobre el control de temperatura (uso de un horno abierto y cerrado); siendo el tratamiento de superficie reconocido tanto en la parte externa (acabado particular por medio del bruñido, alisado burdo, fino y pulido, presentándose en el exterior algunos casos semiengobe y engobe), como en la parte interna (evidencias del alisado burdo, alisado fino, bruñido y pulido, presentando en algunos casos también el semiengobe). Los materiales analizados de los montículos (M4, M5 y M6) varían tanto en forma como en estilos, ello ha generado interpretaciones sobre el rango de popularidad que reflejarían la presencia, aumento y la disminución del nivel de producción y/o posible uso, así como el abandono en la fabricación de ciertas formas por parte de las poblaciones, lo que permite medir de manera diacrónica y sincrónica los cambios en el tiempo (Ford, 1962; Ikehara, 2007); siendo además definidos como cerámica no identificada y Blanco / Rojo (mayor presencia), Lima y Formativo (escasa proporción) (Ver tabla 4 y 5). El cruce de información de los 3 montículos, permitió identificar que los estilos ${ }^{5}$ se ubican cronológicamente dentro del Horizonte Temprano (cerámica con rasgos Formativo), Intermedio Temprano (Blanco/Rojo, Lima y Lumbra), Intermedio Tardío y de filiación no identificado.

\section{ASPECTOS CRONOLÓGICOS Y ESPACIALES DEL UTILLAJE ${ }^{6}$}

Los estudios realizados en la Costa Central (valles del Chillón, Rímac, Chancay y Lurín) señalan que los inicios del Intermedio Temprano (y por ende la cerámica de estilo B/R) estarían referidos hacia los 200 a. C. (Patterson, 1966a, 1966b; Menzel, 1971; Burger, 1993; Silva y García, 1997; Córdova, 1999, 2009), siendo este identificado en el Valle de Chancay: Calera de Jegoan, Cerro Trinidad y Baños de Boza, donde se desarrollaron los primeros intentos de estudio sobre el fenómeno Blanco sobre Rojo (B/R) por parte de Uhle (1904), proponiendo incluso una secuencia cronológica que incluyó el B/R y Proto Lima, asignados al Intermedio Temprano (ver figura 12). En el valle de Chancay los trabajos de Strong (1925) ahondaron las comparaciones morfológicas,

\footnotetext{
4. Las diversas variedades de los tipos de pastas pudieron darse por efectos de cocción que no implica tipos de arcilla, sin embargo al obtener un tipo de arcilla e incluirse diversos desgrasantes se está formando tipos de arcillas, lo que en efecto ha sido identificado durante el análisis de pastas. 
Tabla 1. Distribución porcentual de vasijas de acuerdo a forma-función registrados por UE.

\section{Dispersión de formas}

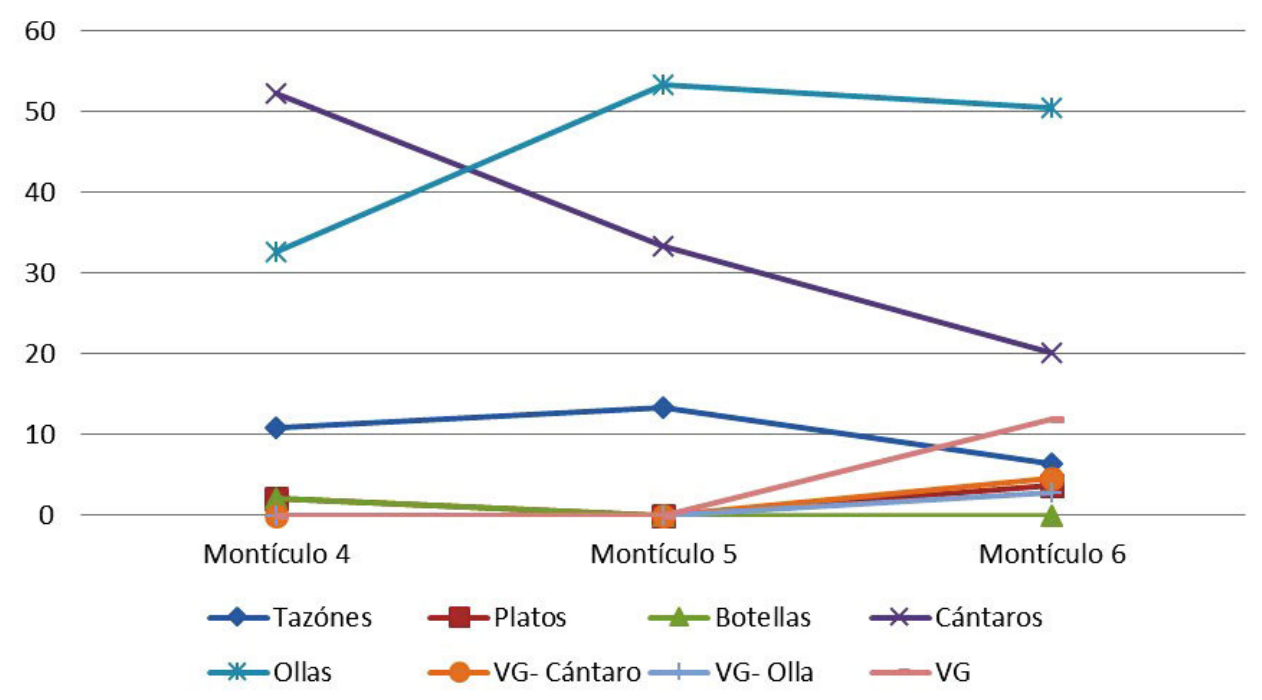

Tabla 2. Cuadro que condensa la distribución porcentual de la forma-función de las vasijas en las UE registrada.

\begin{tabular}{|l|l|l|l|l|l|l|l|l|l|}
\cline { 2 - 9 } \multicolumn{1}{c|}{} & Tazón & Plato & Botella & Cántaro & Olla & $\begin{array}{l}\text { VG- } \\
\text { Cántaro }\end{array}$ & $\begin{array}{l}\text { VG- } \\
\text { Olla }\end{array}$ & VG-VG & Total \\
\hline Montículo 4 & 10.88 & 2.17 & 2.17 & 52.17 & 32.61 & 0.00 & 0.00 & 0.00 & $100 \%$ \\
\hline Montículo 5 & 13.33 & 0.00 & 0.00 & 33.33 & 53.33 & 0.00 & 0.00 & 0.00 & $100 \%$ \\
\hline Montículo 6 & 6.42 & 3.67 & 0.00 & 20.18 & 50.46 & 4.59 & 2.75 & 11.93 & $100 \%$ \\
\hline
\end{tabular}

manifestando que hay rasgos comunes en los platos, cántaros, ollas con cuello corto y cuencos, vinculados al Blanco sobre Rojo (pintura dispuesta en la parte superior) (Strong, 1925; Krober, 1926; Willey, 1943, 1948; entre otros). La evidencia observada en el valle de Chancay ha sido comparada también con los elementos alfareros establecidos por Willey (1943), procedentes de Cerro Trinidad, y los obtenidos por Acero (2015) en Oquendo, donde se ha determinado afinidad tanto en lo estilístico como en la morfología: la formas de olla 1, 2 y 3, se asemejan a las ollas 3 (A y B), 4 (A y B) de Oquendo (montículo 4); la Olla 4 se asemeja a la olla 3 (A y B) (montículo 4) y olla $2 \mathrm{C}$ (montículo 5) de Oquendo; asimismo otra de las formas que presenta mucha similitud es el cuenco, con el cuenco 4 de Oquendo (montículo 4). 
Tabla 3. Resumen comparativo entre las pastas identificadas en cada montículo.

\begin{tabular}{|c|c|c|}
\hline Montículo 4 & Montículo 6 & Montículo 5 \\
\hline \multirow{2}{*}{\multicolumn{3}{|c|}{$\begin{array}{l}\text { Pasta A } \\
\text { Pasta C }\end{array}$}} \\
\hline & & \\
\hline & & \multirow{3}{*}{$\begin{array}{l}\text { Pasta B } \\
\text { Pasta C } \\
\text { Pasta E }\end{array}$} \\
\hline & & \\
\hline & & \\
\hline Pasta B & Pasta A & \\
\hline Pasta D & Pasta B & Pasta A \\
\hline Pasta F & Pasta C & \\
\hline Pasta G & Pasta D & Pasta D \\
\hline \multirow{2}{*}{$\begin{array}{c}\text { Pasta H } \\
\text { Pasta J }\end{array}$} & \multirow{2}{*}{$\begin{array}{l}\text { Pasta E } \\
\text { Pasta F }\end{array}$} & Pasta F \\
\hline & & \\
\hline & Pasta G & \\
\hline & Pasta H & \\
\hline & Pasta I & \\
\hline & Pasta J & \\
\hline \multirow[t]{2}{*}{ Pasta K } & Pasta K & \\
\hline & Pasta L & \\
\hline Pasta E & & \\
\hline Pasta I & & \\
\hline & & Pasta G \\
\hline
\end{tabular}

El utillaje con estilo B/R en el valle bajo del Chillón que expuso Acero (2015), a partir de las investigaciones en el área de Oquendo, demuestra una variedad de formas alfareras cuyos atributos decorativos los asemejan al utillaje de la Secuencia Maestra para la Costa Central (Patterson, 1966b, 2014) (Ver figuras 13, 14 y 15), tal es el caso de la fase Base Aérea referido por platos 1A y 2A que presentan decoración Blanco siendo semejante al plato 1 (M4) de color rojo, y plato 1A (M5) de color negro de Oquendo; por otro lado, se tiene a la olla 1 cuya decoración es Blanco (exterior e interior) semejante a la forma olla 3A de Oquendo (M 4) (sin decoración); y a la olla 2A de color Blanco semejante a la olla 3A de Oquendo (montículo 4) de color rojo (exterior e interior). Una particularidad en la comparación es dada a partir del plato 4A de color Blanco (exterior e interior) y la forma cuenco 1 de Oquendo (M 4), que presenta decoración en color negro sobre fondo rojo asociado a estratos desplazados por acción natural (ENSOS) que indicarían asociación al Formativo (Marcus y Silva, 1988; Silva, Morales y Bragayrac, 1988; Ludeña, 1975; Farfán, 1999; Paredes, 2000; Acero, 2015). 
Tabla 4. Distribución porcentual de los tipos de pastas en los diferentes alfares, en base al total de la muestra.

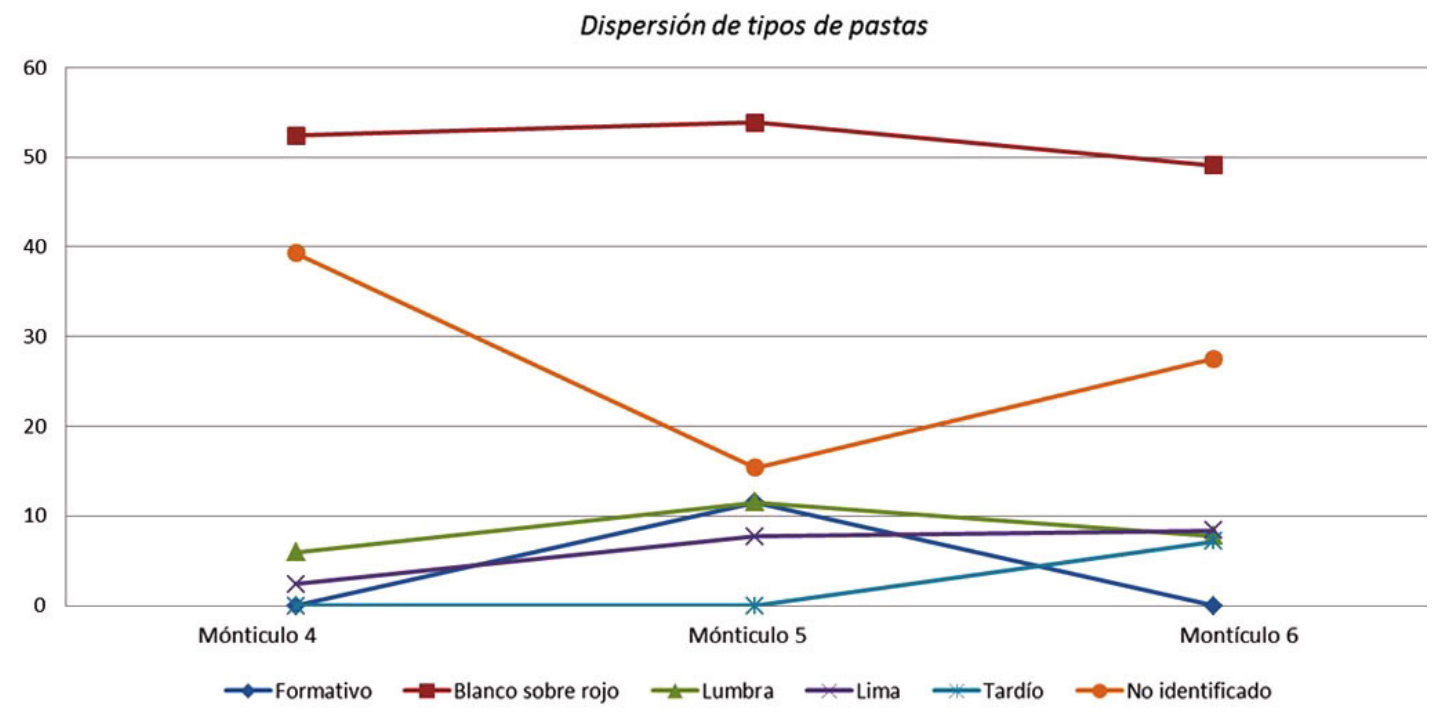

Tabla 5. Cuadro de distribución porcentual de alfares en cada montículo.

\begin{tabular}{|c|c|c|c|c|c|c|c|}
\hline \multicolumn{1}{|l|}{ Pasta Alfar } & Formativo & Blanco sobre rojo & Lumbra & Lima & Tardío & No identificado & Total \\
\hline Montículo 4 & 0.00 & 52.38 & 5.95 & 2.38 & 0.00 & 39.29 & $100 \%$ \\
\hline Montículo 5 & 11.54 & 53.85 & 11.54 & 7.69 & 0.00 & 15.38 & $100 \%$ \\
\hline Montículo 6 & 0.00 & 49.10 & 7.78 & 8.38 & 7.19 & 27.54 & $100 \%$ \\
\hline
\end{tabular}

Durante la fase Base área se evidencia la variante plato (3 A y 1 A) y olla (variedad 1) en el valle bajo del Chillón, que comparada con las formas plato (variedad II 2 y II 5) y ollas (III 2) del sitio Baños de Boza, denotan ciertas afinidades morfológicas denominándose distintamente estilo Baños de Boza para el valle de Chancay (Patterson, 1966b, 2014; Córdova, 1999, 2003, 2009). La fase Polvorín, demuestra cómo se mantienen ciertas formas: el plato $1 \mathrm{~A}$ en color blanco, el cual es semejante a la forma plato 1 de Oquendo (montículo 4); otra de las formas que se presentan en esta fase es la olla 2A con decoración exterior en color Blanco, mientras la olla 3 (A y B) (M 4) y olla 3B (M 5) de Oquendo presentan color marrón (exterior) y rojo-crema (interior); también notamos que la olla $3 \mathrm{~A}$ decorada de color Blanco (exterior) y Rojo (interior), es semejante a la olla 6A en blanco opaco de Oquendo. Estos datos permiten inferir por el tipo de decoración empleada, que sus características nos recuerdan al denominado estilo Lumbra del valle de Chancay. 


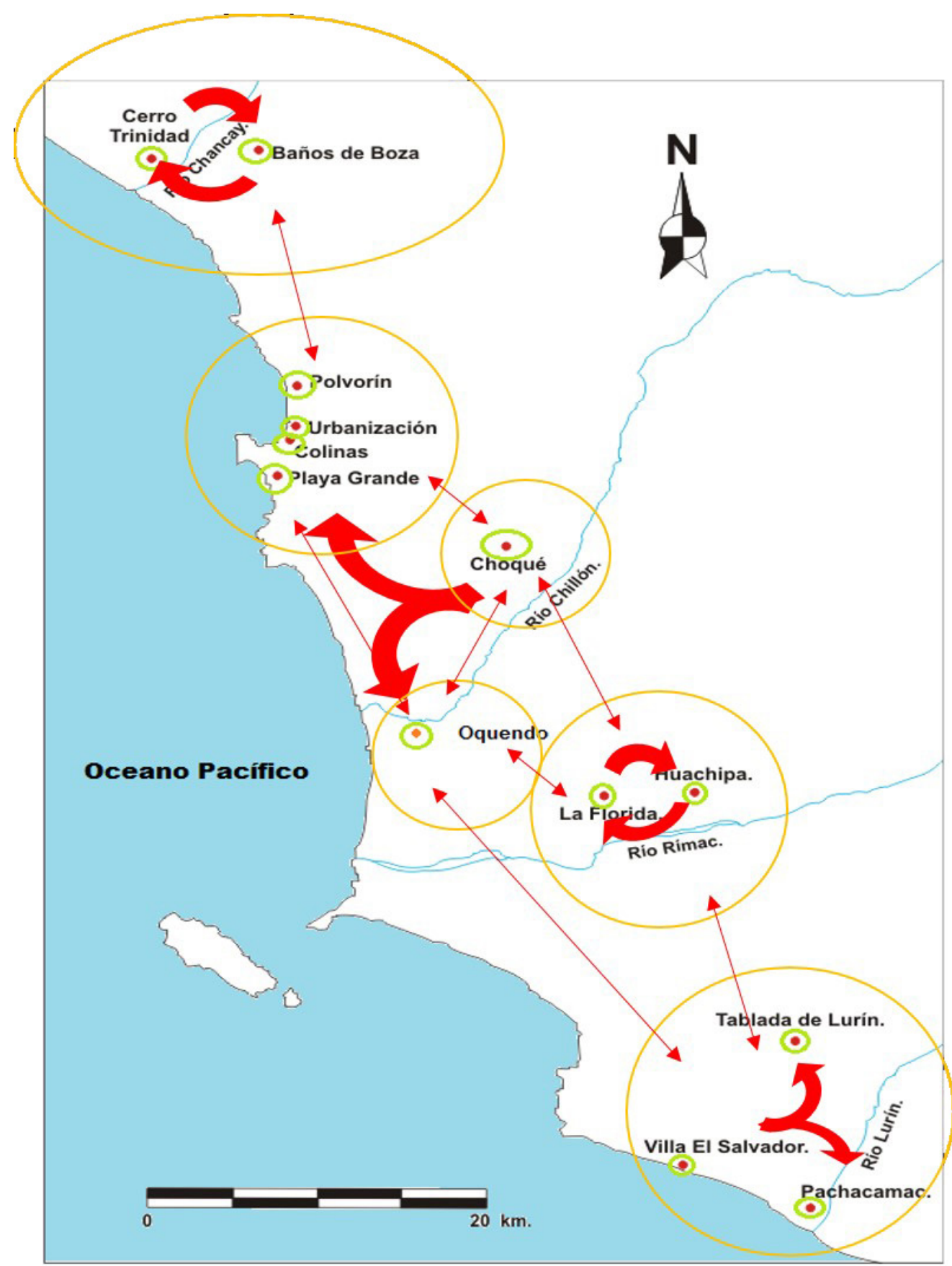

Figura 12. Ubicación de algunos sitios B/R del Periodo Intermedio Temprano, se encerró en color verde espacios sociales y se distribuyó en color anaranjado el espacio geográfico amplio. Resaltando la posible circulación de interacción entre la zona del litoral y las del interior de los valles (flechas rojas gruesas dentro de los valles y flechas rojas delgadas entre los valles). 


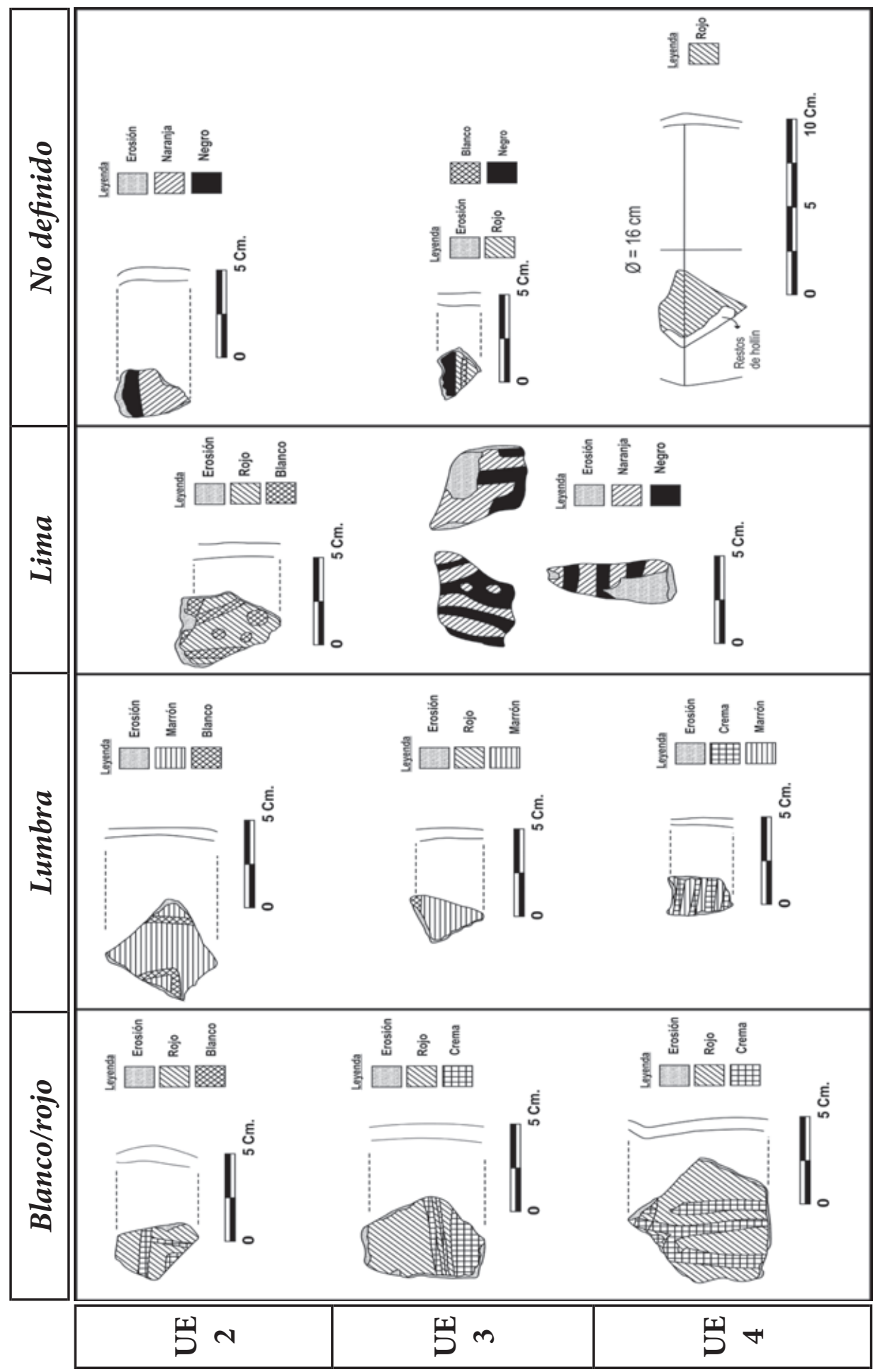

Figura 13. Interpretación de la secuencia estratigráfica y algunos componentes culturales vistos en el montículo 4. 


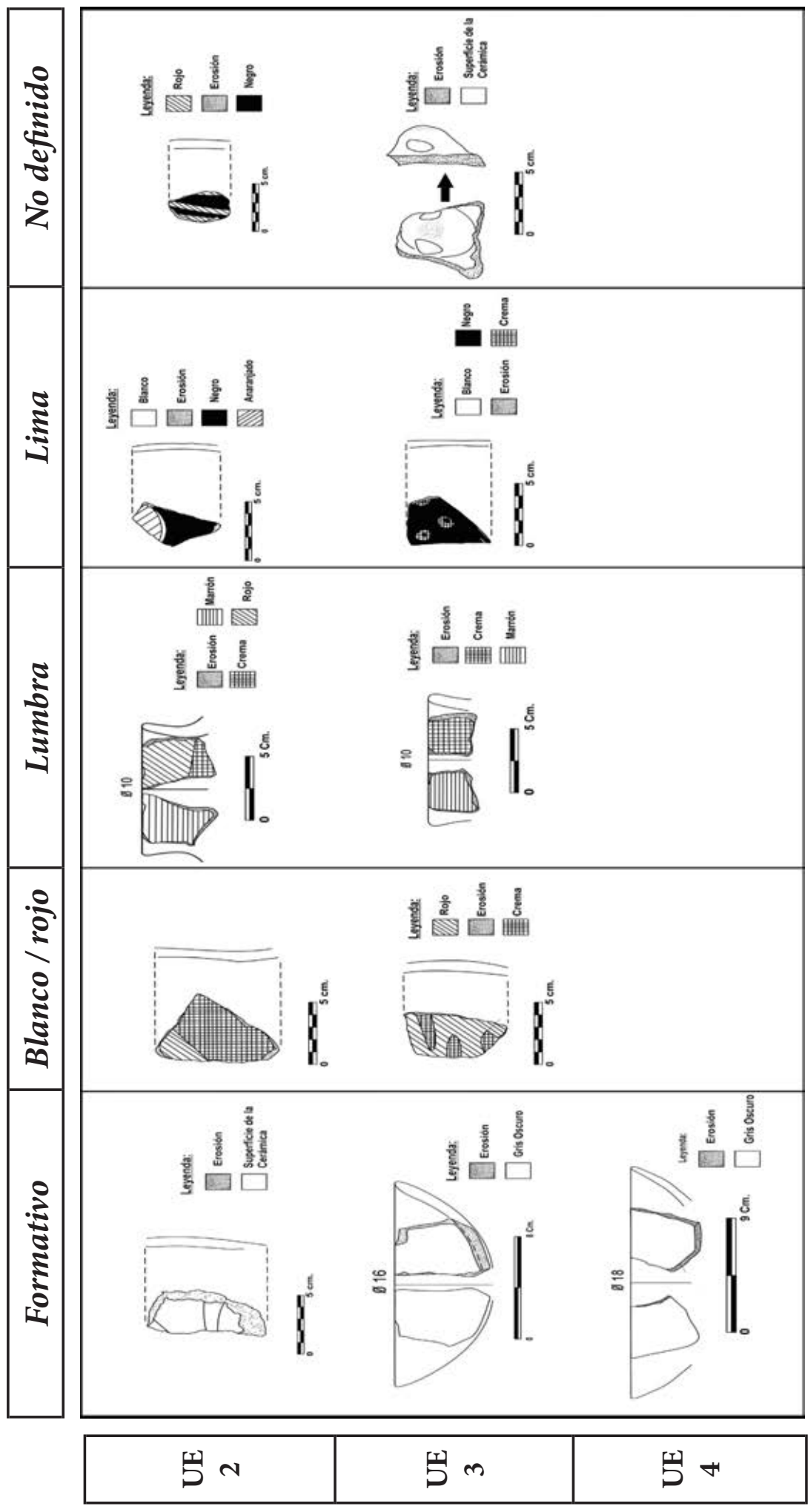

Figura 14. Interpretación de la secuencia estratigráfica y algunos componentes culturales vistos en el montículo 5. 


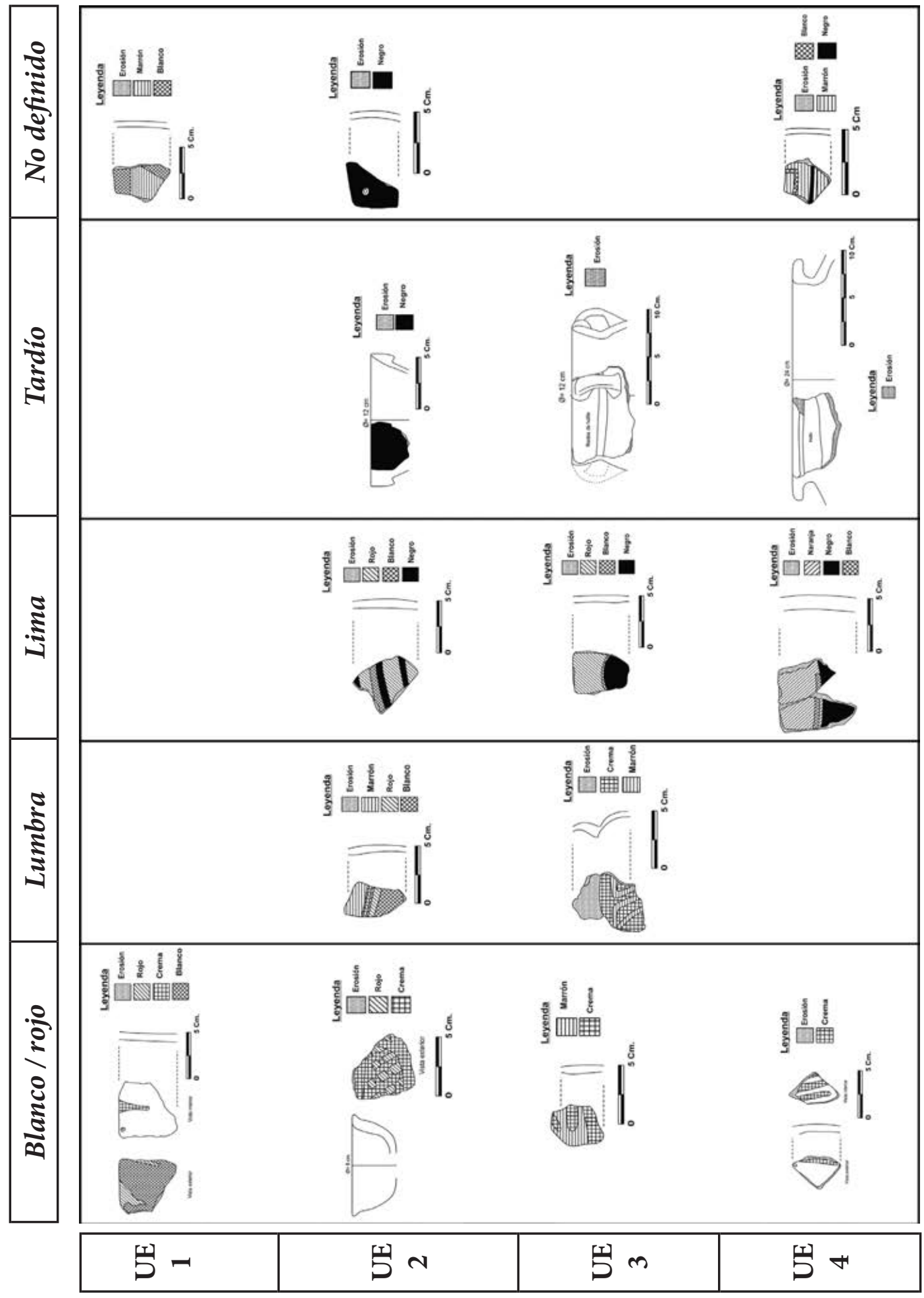

Figura 15. Interpretación de la secuencia estratigráfica y algunos componentes culturales vistos en el montículo 6. 
Para la fase Urbanización se tiene la forma plato 2B, decorado en color blanco, siendo muy semejante al plato 1 de Oquendo (M 4); la variedad de olla 3A decorado con blanco (exterior) y rojo (interior), es semejante a la olla 6A (M 4) de color crema; mientras que la forma plato $2 \mathrm{~B}$ de la fase tricolor y Lima 1, presenta similitud con la forma plato (II 4), el cual se asocia a la última fase de Baños de Boza (Patterson, 1966b, 2014; Córdova, 1999).

Considerando la diversidad del utillaje y decoración que ha sido comparada, podemos indicar que el Blanco sobre Rojo y sus variantes, visto no solo en el valle del Chillón, sino también en el Lurín, Rímac y en Chancay, reportan importancia sobre la amplitud geográfica y diversidad de formas escultóricas en los diversos sitios de la Costa: Huachipa-Jicamarca, Oquendo, Cerro Trinidad, Playa Grande, Ancón, Baños de Boza, entre otros, denotando así que este poria ser considerado como "(...) "variación isocréstica" [que es] entendida como "un espectro de alternativas igualmente equivalentes, de opciones viables para alcanzar el final previsto en la fabricación y/o el uso de objetos materiales" (Sackett, 1990, p. 33). Interpretándose como el resultado de la interacciones que contribuyen en el conocimiento, considerándose que cada sociedad o grupo humano mantiene sus particularidades, siendo sus elementos culturales sensibles a todo tipo de influencia (ideología, el medio, etc.), lo que permitiría entender por qué la evidencia del utillaje B/ R de cada sitio es variable (tanto en los estético y decoración, pero manteniéndose la concepción de la bicromía).

\section{CONCLUSIONES}

Las excavaciones realizadas en los montículos Oquendo (valle bajo del Chillón) dieron claras luces respecto a las ocupaciones tempranas y/o poblaciones que se establecieron en terrenos rodeados por extensos campos propicios para la agricultura, cuya área es fructífera por la cercanía a zonas hídricas y vegetación, el cual permitió el aprovechamiento óptimo de los recursos. De este modo se resalta que el medio geográfico desde un inicio fue importante y permitió el establecimiento de poblaciones y por ende la construcción de los montículos, cuyos contextos denotan una variedad de evidencia arqueológica.

El análisis comparativo en la estratigrafía del valle bajo del Chillón, Oquendo y sitios aledaños; permiten proponer que las poblaciones B/R en el área de los montículos Oquendo se dio antes y después de los fenómenos climáticos que Farfán (1998) interpreta como posible ENSO, ello está referido por los datos identificados tantos en los perfiles de Ancón como en los del M5, M4 y M6, donde se puede identificar los momentos de construcción que permite asignarles una cronología relativa respecto a la antigüedad entre uno y otro montículo, ubicándolo dentro del Periodo Intermedio Temprano.

Lo contextos visualizadas dentro de los montículos permiten considerar que cada uno representa eventos culturales y cronológicos independientes, que sucedieron de manera no secuencial, sin embargo hemos esbozado la correlación de eventos en 
los montículos, lo que nos ha llevado a manifestar que la ocupación se da de manera temprana antes y después de la construcción del M5 y posteriormente en los M4 y M6. Asimismo se manifiesta que cada montículo denota eventos culturales y cronológicos independientes, que sucedieron de manera no secuencial y/o lineal: mientras se construía un montículo se pudieron estar realizando actividades paralelas en otro.

Dentro de Oquendo al parecer se han marcado dos áreas de actividades diferenciadas, la primera corresponde a áreas de uso doméstico como es el caso del M5 y M4, que tuvo quizás un carácter precario (por lo temporal de su empleo), identificándose concentraciones de restos quemados, ceniza y escasos restos vegetales (contexto primario), asociados estratigráficamente a formas alfareras de tipo ollas y cántaros B/R. Mientras el M6 evidenció, restos de una arquitectura casi totalmente destruida asociada a un probable uso residencial, representado por los restos de pisos y muros que se han observado, cuya evidencia estratigráfica muestra formas alfareras de filiación diversa, producida tras las alteraciones y mezclas de depósitos durante las reocupaciones tardías.

La ocupación evidencia en Oquendo corresponde a un grupo social denominado población Blanco sobre Rojo quienes se asentaron y generaron esferas culturales que interactuaron con otras poblaciones.

Agradecimientos: La investigación surgió a partir de las discusiones sobre los grupos tempranos y su dinámica poblacional durante el Periodo Intermedio Temprano en el valle bajo del Chillón, que fue presentada, de manera extensa, y sustentada para la tesis a finales del año 2015. Labor realizada con apoyo del arqueólogo Carlos Farfán Lobatón.

\section{REFERENCIAS BIBLIOGRÁFICAS}

Acero, E. (2010 a). Investigaciones Arqueológicas en los Montículos Oquendo, Predio 18 de la UNFV La Secuencia Maestra de Patterson y su aplicación al valle bajo del Chillón. (Informe Técnico Preliminar Pre - Profesional N 1). Universidad Nacional Federico Villarreal. Lima.

Acero, E. (2010 b). La Tecnología Alfarera del Blanco sobre Rojo y su presencia en el valle bajo del Chillón. (Informe Técnico Final Pre - Profesional N² 2). Universidad Nacional Federico Villarreal. Lima.

Acero, E. (2015). Investigaciones arqueológicas en Oquendo, valle bajo del Chillón La secuencia del utillaje identificado en los montículos 4, 5 y 6. [Tesis de Licenciatura en Arqueología. Universidad Nacional Federico Villarreal. Lima].

Acero, E. (2018). Acercamiento a la población del sitio arqueológico de Oquendo, valle bajo del río Chillón. Editorial Académica Española. 
Burger, R. (1993). La evidencia Radiocarbónica para la antigüedad de Chavín de Huántar. Emergencia de la Civilización en los Andes. R. Burger (Ed.). Universidad Nacional Mayor de San Marco. Lima

CDIAG. (1993). La Cuenca del Chillón, Diagnóstico para un Plan Integral de Desarrollo. Centro de Información y Desarrollo Integral de Autogestión. Lima

Córdova C., H. (1999). Baños de Boza Cronología y Estilo de la Tradición Blanco sobre Rojo [Tesis de Licenciatura en Arqueología. PUCP]. Lima

Córdova C., H. (2003). La cerámica Blanco sobre Rojo en el Valle de Chancay y sus relaciones con el estilo Lima. Bulletin de l'Institut Francais d' Études Andines, 32(1), 69 - 100. IFEA. Lima

Córdova C., H. (2009). La Arquitectura y Cronología de Baños de Boza, Valle de Chancay y sus implicancias para fines del Horizonte Temprano en el valle de Lurín. R. Burger \& K. Makowski (Ed.). Arqueología del Periodo Formativo en la Cuenca baja del Lurín. Editorial PUCP. Lima

Farfán L., C. (1998). Informe Preliminar de Avance de las Ejecución del Proyecto de Investigación Arqueológica en Oquendo. (Informe Preliminar $N^{\circ} 1$ ). Universidad Nacional Federico Villarreal. Lima

Ford, J. (1962). Método para establecer Cronologías Culturales. Manuales Técnicos III. Unión Panamericana. Washintong, D. C.

Goldhausen, M. (2014). Una Aproximación a la Secuencia Estilística de la cerámica del Desarrollo Regional en la Costa Central desde la perspectiva de la Quebrada de Orcón - Pacaybamba. En J. Narváez \& O. Pinedo (Eds.). Patrón y Proceso en la Cerámica del Periodo Intermedio Temprano de la Costa Central del Perú, Avqui Ediciones. Lima

Ikehara T., H. C. (2007). Festines del Periodo Formativo Medio y Tardío en Cerro Blanco de Nepeña [Tesis inédita de Licenciatura en Arqueología. PUCP]. Lima

Kroeber, A. (1926). The Uhle Pottery Collection from Nieveria. Publications in American Archaeology and Ethnology, 21(7). University of California Press Berkeley

Lanning, E. (1960). Chronological and Cultural Relationships of Early Pottery in Ancient Perú (Dissertation Ph. D.). University of California Press Berkeley

Lanning, E. (1963). An Early Pottery Collection fron Ancon, Central Coast of Perú. Nawpa Pacha, 1, pp. 47 - 60.

Ludeña R. H. (1975). Secuencia Cronológica y Cultural del Valle del Chillón [Tesis inédita de Doctor en Arqueología]. Programa Académico de Ciencias Sociales. Universidad Nacional Mayor de San Marcos. Lima

Oficina Nacional de Evaluación de Recursos Naturales (ONERN). (1970). Inventario y Evaluación de los Recursos de la Zona del Proyecto Marcapomacocha. Estudio de las 
Cuencas de los Ríos Chillón, Rímac y Lurín, 1 y 2. Instituto Nacional de Planificación. Oficina Nacional de Evaluación de Recursos Nacionales. Lima

Oficina Nacional de Evaluación de Recursos Naturales (ONERN). (1975). Inventario y Evaluación de los Recursos Naturales. ONERN. Lima

Palacios L., J. (1987). Secuencia de la cerámica temprana del valle de Lima en Huachipa. Gaceta Arqueológica Andina, 4(16), 24 - 31. Lima

Palacios L., J. (1988). La Secuencia Cerámica Temprana del Valle de Lima en Huachipa. Gaceta Arqueológica Andina, (16), 13 - 24. Lima

Paredes O., J. (2000). La Cultura Lima en el Valle Bajo del Chillón. Arqueología y Sociedad, (13), 133 - 158. Museo de Arqueología y Antropología UNMSM. Lima

Patterson, T. (1966 a). Early Cultural Remains on the Central Coast of Perú. Ñawpa Pacha, (4), 145 - 153.

Patterson, T. (1966 b). The Chillón Valley. Pattern and Process in the Early Intermediate Period Pottery of the Central Coast of Peru, University of California Publication in Anthropology 3. Berkeley \& Los Angeles

Patterson, T. (2014). Patrón y Proceso en la Cerámica del Periodo Intermedio Temprano de la Costa Central del Perú. (Traducción), J. Narváez \& O. Pinedo (Ed.). Avqui Ediciones, Lima

Pulgar Vidal, J. (1987). Geografía del Perú. 9 Edición. Editorial Inca S.A., Lima

Pulgar Vidal, J. (1996). Geografía del Perú. Las ocho Regiones Naturales 10, PEISA, Lima

Sackett, J. (1990). Style and ethnicity in archaeology: a case for isochrestism. En Conkey y C. Hastorf (Eds.). The uses of style in archaeology. Cambridge University Press, England

Silva, J., Hirth, K., García, R. \& Pinilla, J. (1983). El Formativo en el Valle del Rímac: Huachipa - Jicamarca. Arqueología y Sociedad, (9), 1-92. Museo de Arqueología y Etnología UNMSM. Lima

Silva, J. \& Marcus, J. (1988). Cocales en el valle del Chillón. Evidencia arqueológica y contexto ecológico. Rostworowski, Maria. Conflicts over coca field en XVI Century memories of Museum of Anthropology of Michigan

Silva, J., Morales, D., García, R. \& Bragayrac, E. (1988). Cerro Culebra, un sentamiento de la época Lima en el Valle del Chillón. Boletín de Lima, 56, pp. 23 - 33. Lima

Silva, J. \& García, R. (1997). Huachipa-Jicamarca: Cronología y Desarrollo Sociopolítico en el Rímac. Boletín del Instituto Francés de Estudios Andinos, 26(2), 195-228. IFEA. Lima 
Strong, D. (1925). The Uhle Pottery Collections from Ancón. University of California, Publications in American Archaeology and Ethnology 21(4). California Press Berkeley.

Stumer, L. (1954a). The Chillon Valley of Peru: Excavations and Reconnaissance 1952 - 1953. Archaeology, 7(3), 171 - 178

Stumer, L. (1954b). The Chillon Valley of Peru: Excavations and Reconnaissance 1952 - 1953. Archaeology, 7(4), 220 - 228.

Willey, G. (1943). Excavations in the Chancay Valley. Archaeological Studies in Perú, 1941 1942. University Press New York. Columbia

Willey, G. (1948). A Functional Analysis of Horizon Styles. Peruvian Archaeology. Memoirs of the Society of American Archeology, (4), 8-15. Menasha

\section{SOBRE LOS AUTORES}

\section{Erick Ernesto Acero Shapiama}

Bachiller y licenciado en la especialidad de arqueología por la Universidad Nacional Federico Villareal. Actualmente cursa la Maestría Gestión Cultural, Patrimonio y Turismo, en la Universidad San Martín de Porres; Cuenta con cursos de especialización en Gestión Pública, EIA y Monitoreo Ambiental, y Gestión para Relaciones Comunitarias; con amplia experiencia en dirección y ejecución de proyectos de investigación en arqueología Andina.

\section{Lisseth F. Rojas Pelayo}

Arqueóloga egresada de la Universidad Nacional Federico Villarreal, con más de 10 años de experiencia en investigación; tiene estudios especializados de bioarqueología por la Universidad de Murcia, y la Complutense de Madrid en convenio con la UNMSM. Es investigadora asociada del Proyecto Maranga y Cruz Punta; jefe de campo y parte del equipo de investigadores del Programa Chavín de Huántar.

Junto con Erick Ernesto Acero ha escrito sobre los resultados de la campaña I del "Proyecto de Investigación Arqueológica Cruz Punta (en prensa) (2020); el libro: "Acercamiento a la población del sitio arqueológico Oquendo" (2018). Asimismo ha realizado presentaciones en el SAA 84th Annual de Albuquerque, el tema de "Chavín after Chavín: Funerary Facts through the voices of its Protagonists Architectural Sequences and Ocupational Events in the Ceremonial Center Chavin de Huantar during Formative Period (2018) y en el VII PAMINSA - "Vida y Muerte en el desierto de Atacama" (2017), entre otros. 